\title{
FRACTURE BEHAVIOUR, STRUCTURE AND MECHANICAL PROPERTIES OF A508 GR. 4N CLASS 3 GRADE STEEL.
}

\author{
Ladislav KANDER ${ }^{1}$, Šárka STEJSKALOVÁ ${ }^{1}$, Petr ČíŽEK ${ }^{1}$ \\ 'MATERIÁLOVÝ A METALURGICKÝ VÝZKUM s.r.o., Pohraniční 693/31, 70300 Ostrava-Vitkovice, Czech \\ Republic, EU, ladislav.kander@mmvyzkum.cz
}

https://doi.org/10.37904/metal.2020.3534

\begin{abstract}
Recent increase in output of nuclear power plant has been attained by enlargement of most major components such as pressure vessels. Such large components have almost reached a size limit from the points of manufacturing capacity. In order to solve this problem, it must be beneficial to apply by use of material of higher strength, which brings reduction of pressure vessel thickness and weight A508 Grade 4N is a high nickel pressure vessel steel with relatively high yield strength and a relatively low transition temperature. $A$ study was undertaken to evaluate conventional as well as unconventional material properties of forging made of in our institute. This paper describes results of mechanical properties, structure and fracture behavior including nil-ductility transition temperature.
\end{abstract}

Keywords: A508 Grade 4N, Transition behavior, Mechanical Properties

\section{INTRODUCTION}

A508 Grade $4 \mathrm{~N}$ is a high nickel (3.4\%) pressure vessel steel with a relatively high yield strength and a relatively low transition temperature. Steel has an attractive combination of strength and low temperature fracture toughness. The high nickel content and refined microstructure result in a steel with excellent combination of strength, toughness and low ductile-to brittle transition temperature. A study was undertaken to evaluate conventional as well as unconventional material properties of forging made of in our institute. This paper describes results of mechanical properties, structure and fracture behaviour including nil-ductility transition temperature. Main motivation for this work was to verify of metallurgy and production technology for manufacturing of forging with sufficient metallurgical parameters as well as sufficient level of mechanical properties especially from the view of toughness.

\section{MATERIAL, TEST PROCEDURES AND RESULTS}

An ingot V2A with total weight $1600 \mathrm{~kg}$ was produced in our institute according to ASTM A 508 [1] with VCD process. Chemical composition of ingot can be seen in Table 1.

Table 1 Basic chemical composition of the steel, wt $\%$

\begin{tabular}{|c|c|c|c|c|c|c|c|c|}
\hline $\mathrm{C}$ & $\mathrm{Mn}$ & $\mathrm{Si}$ & $\mathrm{P}$ & $\mathrm{S}$ & $\mathrm{Cu}$ & $\mathrm{Ni}$ & $\mathrm{Cr}$ & $\mathrm{Mo}$ \\
\hline 0.09 & 0.27 & 0.08 & 0.011 & 0.008 & 0.09 & 3.75 & 1.68 & 0.48 \\
\hline
\end{tabular}

\begin{tabular}{|c|c|c|c|c|c|c|c|c|}
\hline $\mathrm{V}$ & $\mathrm{Ti}$ & $\mathrm{As}$ & $\mathrm{Sn}$ & $\mathrm{Sb}$ & $\mathrm{Al}$ & $\mathrm{Nb}$ & $\mathrm{N}$ & $\mathrm{O}$ \\
\hline 0.008 & 0.006 & 0.005 & 0.004 & 0.003 & $<0.010$ & 0.003 & 0.0029 & 0.0052 \\
\hline
\end{tabular}


After forging in VITKOVICE HEAVY MACHINERY on final dimensions $(150 \times 250 \times 1800 \mathrm{~mm})$ and before final heat treatment specimens were cut to construct continuous cooling transformation diagram (CCT). The basis of a parameter selection many heat treatment operations is knowledge of the supercooled austenite transformation kinetic during the cosines cooling from the austeninitizing temperature. The obtaining of the optimum properties of the steel is possible only after the application of suitable heat treatment operations. Sample is austenitized and then cooled at a predetermined rate and the degree of transformation in measured using special equipment - dilatometer. Obviously, a large number of experiments are required to build up a complete CCT diagram. CCT diagram for steel under investigation is given in the Figure 1.

After final heat treatment containing austenitization at $890{ }^{\circ} \mathrm{C}$ following water quenching and tempering at $650^{\circ} \mathrm{C}$ with cooling on air both tensile tests and impact tests have been carried out. Results of basic mechanical properties (tensile test at room temperature and impact tests at $-29^{\circ} \mathrm{C}$, which is ASME specified temperature) are summarized on Table 2. Based on successful test results macro and microstructure analysis, inclusion content, following by testing of unconventional properties (FATT, $T_{N D T}, R T_{N D T}$ transition temperatures as well as evaluation of fracture behaviour with fracture mechanics tests could be started. Results of macrostructure investigation are presented in Figure 2.

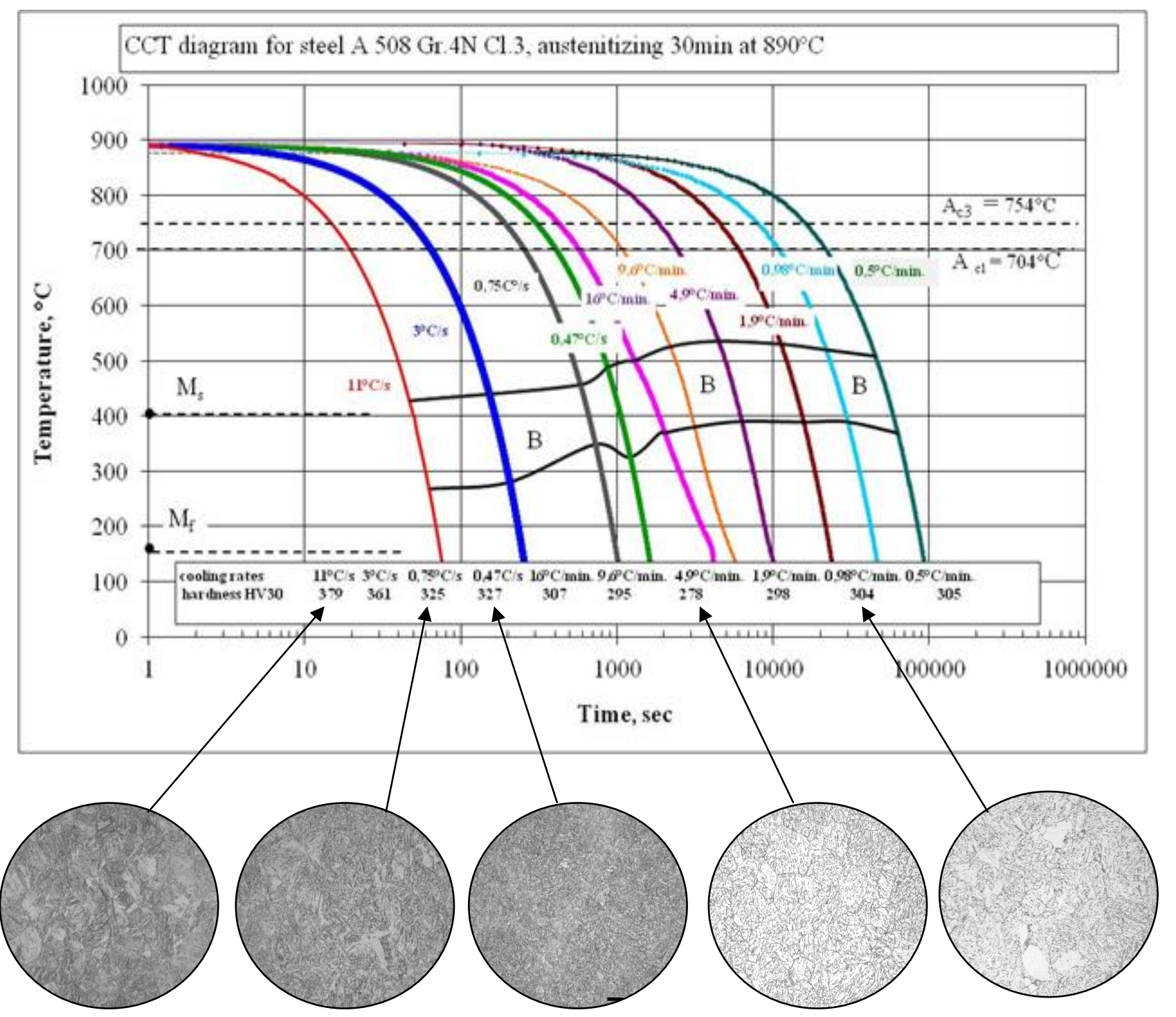

Figure 1 CCT diagram of A $508 \mathrm{Gr} .4 \mathrm{~N} \mathrm{Cl.3}$ steel with examples of microstructure 
Table 2 Mechanical properties of the steel A508 Gr.4N Cl.3

\begin{tabular}{|c|c|c|c|c|c|}
\hline Steel grade & $\begin{array}{c}\mathrm{Rp} 0.2 \\
{[\mathrm{MPa}]}\end{array}$ & $\begin{array}{c}\mathrm{Rm} \\
{[\mathrm{MPa}]}\end{array}$ & $\begin{array}{c}\mathrm{A} \\
{[\%]}\end{array}$ & $\begin{array}{c}\mathrm{Z} \\
{[\%]}\end{array}$ & $\begin{array}{c}\mathrm{KV}-29^{\circ} \mathrm{C} \\
{[\mathrm{J}]}\end{array}$ \\
\hline A508 Gr.4N Class3 & 536 & 638 & 23 & 74 & 230 \\
\hline ASME requirements & min. 485 & $620-795$ & min. 20 & min. 48 & 48 \\
\hline
\end{tabular}

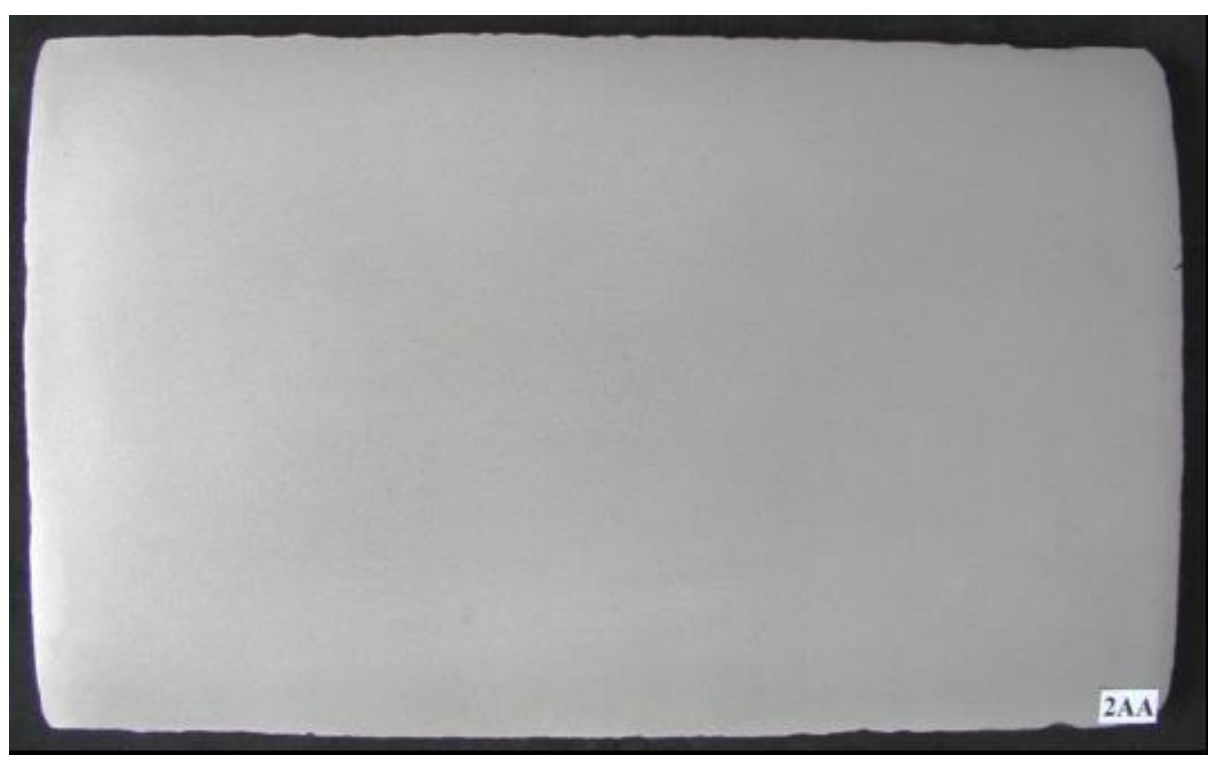

Figure 2 Macrostructure of steel A508 Gr.4N Cl.3 after final heat treatment

Inclusion content has been determined according to ASTM E 45 [2], which is well known test method covers procedure for determining the non-metallic inclusion content of wrought steel. For evaluation was used method A (worst fields). Each field was compared to the square fields depicted in Plate I-r a search for the worst field, that is, the highest severity rating, of each inclusion type A, B, C, and D for both the Thin and Heavy series. The severity level of these worst fields was reported for every specimen examined, here however due to space reason only average results are reported in Table 3.

Table 3 Inclusion content of the A508 Gr.4N Cl.3 grade steel

\begin{tabular}{|c|c|c|c|c|c|c|c|}
\hline \multicolumn{8}{|c|}{ Worst field (method A) } \\
\hline \multicolumn{2}{|c|}{ Type A } & \multicolumn{2}{c|}{ Type B } & \multicolumn{2}{c|}{ Type C } & \multicolumn{2}{c|}{ Type D } \\
\hline Thin & Heavy & Thin & Heavy & Thin & Heavy & Thin & Heavy \\
\hline 1.2 & 0.6 & 1.1 & 0.8 & 0 & 0 & 1.25 & 0.3 \\
\hline
\end{tabular}

To obtain more information about transition range of steel under investigation series of Charpy impact tests have been carried out to evaluate position of transition range on temperature axis and quantify all most widely used transition temperature. Results of Charpy impact tests are plotted in the form of temperature dependence of impact energy in the Figure 3.

Similar dependencies were obtained both for percent of shear fracture and lateral expansion. From these dependencies transition temperatures were calculated - see Table 4. Two last columns in Table 4 represent nil ductility temperature evaluated according to ASTM E 208 [3] and reference nil ductility temperature RT NDT that make connection between results of drop weight tests and Charpy impact test. For details of RT NDT evaluation see ASME Code [4]. 


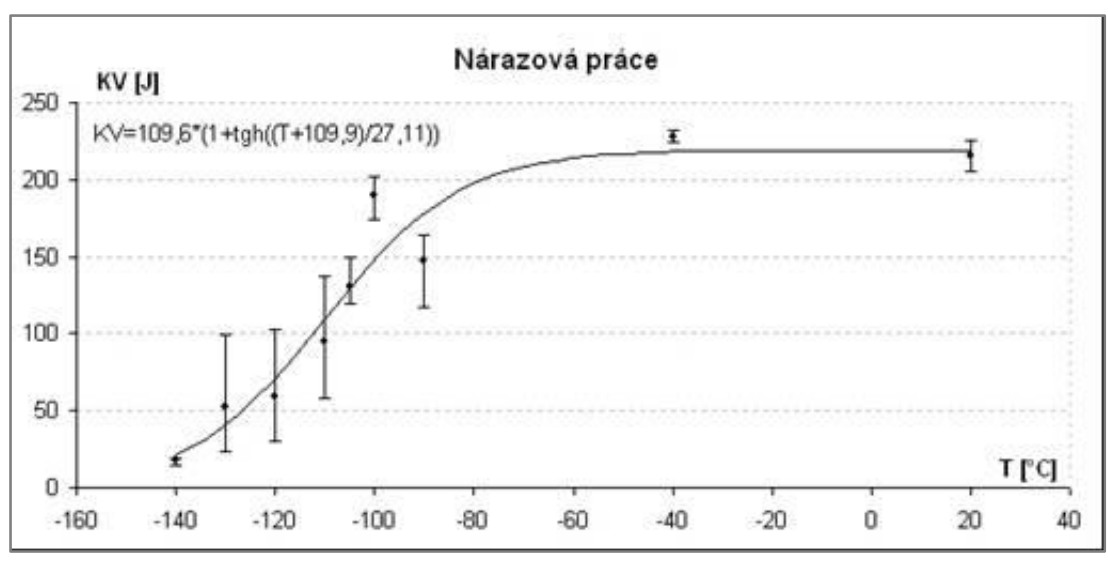

Figure 3 Temperature dependence of impact energy

Table 4 Transition temperatures of steel under investigation

\begin{tabular}{|c|c|c|c|c|c|c|}
\hline $\mathbf{T}_{27} \mathrm{~J}$ & $\mathbf{T}_{41} \mathrm{~J}$ & $\mathbf{T}_{68} \mathrm{~J}$ & $\mathbf{F A T T}$ & $\mathbf{T}_{0.9 \mathrm{~mm}}$ & $\mathbf{R T}_{\text {NDT }}$ & $\mathbf{T}_{\text {NDT }}$ \\
\hline$-138^{\circ} \mathrm{C}$ & $-130^{\circ} \mathrm{C}$ & $-121^{\circ} \mathrm{C}$ & $-114^{\circ} \mathrm{C}$ & $-120^{\circ} \mathrm{C}$ & $-115^{\circ} \mathrm{C}$ & $-120^{\circ} \mathrm{C}$ \\
\hline
\end{tabular}

Recently developed so called Master curve concept based on evaluation of reference temperature $T_{0}$ was used for evaluation of fracture behaviour $[5,6]$. In this concept modern statistical methods, and an improved understanding of elastic-plastic test methods, have been coupled to define a transition curve of static fracture toughness versus temperature that is derived using only fracture mechanics-based test data. Main advantage is that uncertainty associated with the empirical postulates involving non-fracture mechanics data that had to be employed in the past for ASME Code has been eliminated. ASTM E 1921 [6] presents now the experimental and computational procedures that are to be used to arrive at a reference temperature, $\mathrm{T}_{0}$. Temperature $T_{0}$ is defined as the temperature at which a set of data having six or more valid $\mathrm{K}_{\mathrm{JC}}$ values converted to $25.4 \mathrm{~mm}$ size equivalence will have a median $100 \mathrm{MPa} \cdot \mathrm{m}^{0.5}$. Master curve is an empirically derived universal transition range curve of fixed shape for static fracture toughness versus temperature. It is known to characterize the transition range of commercially made ferritic steels and weld metals. The Master curve essentially verifies the ASME postulate, differing principally in the reference temperature indexing method, using $\mathrm{T}_{0}$ instead of RT $\mathrm{T}_{\mathrm{NDT}}$ and a median transition curve shape instead of $K_{I C}$ lower bound. Fracture toughness tests were carried out at test temperature $-140^{\circ} \mathrm{C}$ to obtain median of fracture toughness about $100 \mathrm{MPa} \mathrm{m}^{0.5}$. Based on experimental data Master curve with tolerance bounds for fracture probability correspond to 5 and $95 \%$ have been plotted in the Figure 4.

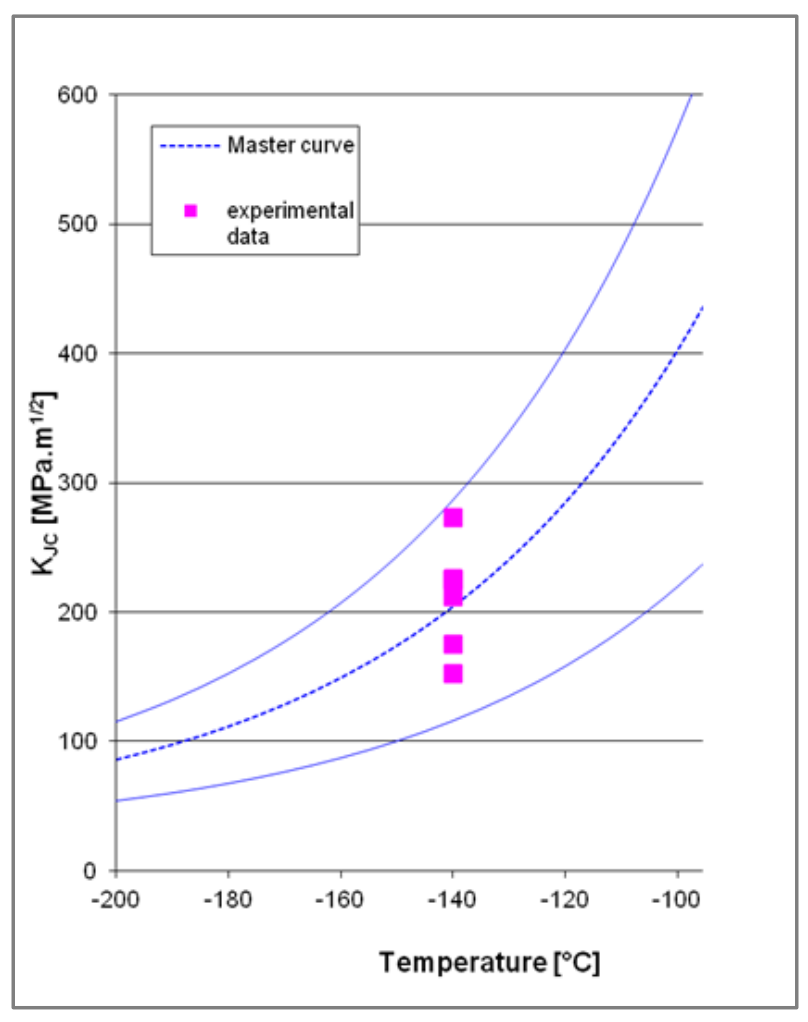

Figure 4 Master curve of steel A508 Gr.4N Cl.3 (including tolerance bounds for 5 and $95 \%$ fracture probability 


\section{RESULTS AND DISCUSSION}

\subsection{Structure and mechanical properties}

Microstructure of the steel under investigation was found to be fully bainitic in whole range of cooling rates see CCT diagram - Figure 1. Only two cooling rates with $-v=4.43$ and 4.73 respectively (correspond 0.98 and $0.5{ }^{\circ} \mathrm{C} / \mathrm{min}$ ) showed a very small amount of ferrite localized mostly in small isles. Total amount of ferrite has been found to be below $2 \%$. Macrostructure analysis shows, that structure is clear without any segregation. From the Table 3 can be clearly seen that non-metallic inclusion content characterized by worst field method is good and indicates sufficient level of metallurgy during production. These results are in very good accordance with reference [7].

Mechanical properties summarized in Table 2 meet all requirements with sufficient level. During this work several tempering temperatures have been chosen to get information about structure and properties including toughness in wide interval. Tempering temperature $650{ }^{\circ} \mathrm{C}$ was chosen from the point of view maximum toughness level.

\subsection{Impact properties and fracture toughness}

Excellent toughness was confirmed by Charpy impact tests, temperature dependencies of all characteristics earned from Charpy impact tests declared very low transition temperatures (see Table 4) usually used for toughness characterization of pressure vessel steels used in nuclear power engineering. Additionally, nil ductility temperature as well as its normalized value $\mathrm{RT}_{\mathrm{NDT}}$ also confirmed perfect toughness properties. Our results are on the same level or better compared with [8].

Temperature dependence of fracture toughness has been presented in the form of Master curve - see Figure 4. Value of evaluated reference temperature agree very well with results presented in [9] where large comparison of available fracture toughness data was carried out from the point of view variability of fracture toughness in the transition range. Based on experimental data from more than 800 fracture toughness test results a new model describing behavior of $\mathrm{A} 508 \mathrm{Gr} .4 \mathrm{~N}$ has been introduced in [9]. Our experimental results completely agree with the findings presented in [9].

\section{CONCLUSION}

Paper summarized results of structure analysis and mechanical properties including fracture toughness data for A508 Grade 4N Class 3 pressure vessel steel. Obtained results show on good metallurgical level during manufacturing process. Heat treatment was primarily focused on optimizing toughness properties characterized by low transition temperatures based on Charpy as well as on DWT tests. Transition temperatures have been found to be between -138 and $-114^{\circ} \mathrm{C}$. Fracture toughness was characterized using recent concept called Master curve approach based on evaluation of reference temperature $T_{0}$. Value of reference temperature $\mathrm{T}_{0}$ was found to be $-188^{\circ} \mathrm{C}$ and also confirmed excellent toughness properties of the steel under study. Our results are in a very good agreement with results presented in references [7-9].

\section{ACKNOWLEDGEMENTS}

This paper was created in the frame of the Institutional support for long-term and conceptual development of a research organization in 2019, provided by the Ministry of Industry and Trade of the Czech Republic.

\section{REFERENCES}

[1] ASME Code section II, part A Specification for quenched and tempered vacuum-treated carbon and alloy steel forgings for pressure vessels, SA-508/SA-508M (identical with ASTM specification A508/A508-05b), 200.7 
[2] ASTM E 45 Standard Test Method for Determining the Inclusion Content of Steel.

[3] ASTM E 208 Standard Test Method for Conducting Drop-Weight Test to Determine Nil-Ductility Transition Temperature of Ferritic Steels.

[4] ASME Boiler and Pressure Vessel Code. An American National Standard, Sect.XI, Rules for Inservice Inspection of Nuclear Power Plant Components, Article A-4000, American Society of Mechanical engineers, New York, 1993

[5] McCABE, D.E., MERKLE, J.G.,WALLIN, K. An Introduction to the Development and Use of the Master Curve Method. New York: ASTM International, 2005.

[6] ASTM E 1921 Standard Test Method for Determination of Reference Temperature, To, for Ferritic Steels in the Transition Range.

[7] SUZUKI, K.,KURIHARA,i.,SASAKI, T., KOYOMA, Y.,TANAKA,Y. Application of High Strength MnMoNi Steel to Pressure Vessel for Nuclear Power Plant. Nuclear Engineering and Design. 2001, vol. 206, pp. 261-278.

[8] STOFANAK, R. J., POSKIE, T.J., LI, Y.Y., WIRE, G.L. Irradiation Damage Behavior of Low Alloy Steel Wrought and Weld Materials. Westinghouse Electric Corporation Bettis Laboratory, West Mifflin, PA 15122.

[9] LEAX, T.R. Temperature Dependence and Variability of Fracture Toughness in the Transition Regime for A508 Grade 4N Pressure Vessel Steel. 